\title{
Anticipatory grief among close relatives of patients with Parkinson's Disease
}

\author{
Ulf Erland Johansson ${ }^{1}$, Agneta Grimby ${ }^{2}$ \\ ${ }^{1}$ Department of Medicine, Sahlgrenska Academy, Gothenburg University, Gothenburg, Sweden \\ ${ }^{2}$ Department of Geriatrics, Sahlgrenska Hospital, Gothenburg, Gothenburg, Sweden
}

\author{
Email address: \\ agneta.grimby@telia.com (A. Grimby)
}

To cite this article:

Ulf Erland Johansson, Agneta Grimby. Anticipatory Grief among Close Relatives of Patients with Parkinson's Disease. Psychology and Behavioral Sciences. Vol. 3, No. 5, 2014, pp. 179-184. doi: 10.11648/j.pbs.20140305.15

\begin{abstract}
Several illnesses cause suffering and pre-death grief among close relatives, as in cancer and dementia. This might be the case also at Parkinson's Disease (PD). We aimed at getting grief self-reports of relatives of PD patients using the same instrument (AGS) as in former grief studies to see similarities and differences. Anticipatory Grief Scale (AGS) and questions about background variables were sent to PD caregiver support groups in Sweden to be handed out to the members at their meetings. Close relatives of persons with Parkinson's disease (PD) reported feelings and reactions on the AGS, and the results were compared with those from relatives of dementia patients in a former study also using the AGS. Self-estimations about the duration of illness, the condition at the time for questioning, and the perceived quality of care of the relative with PD were also made. The study showed an overall stressful situation including feelings of missing and longing, inability to accept the terminal fact, preoccupation with the ill, tearfulness, sleeping problems, anger, loneliness, and a need to talk. The PD and dementia groups appeared to show much more anticipatory grief similarities than dissimilarities. The duration of the disease did not influence the grief reactions, which, however, was shown for perceived quality of care as regards irritability and preoccupation thinking of the ill relative. Also the respondents' perception of a bad condition of their relatives showed increased reports on loneliness, a need to talk about the illness, personal dysfunction, and not planning ahead.
\end{abstract}

Keywords: Parkinson's Disease, Close Relatives, Anticipatory Grief, Psychology

\section{Introduction}

Parkinson's disease (PD) is a progressive neurological disease with individual symptoms. The negative influence on the marital relationship when a spouse is diagnosed with Parkinson's disease is evident according to many studies (1). The pattern of burden, the risk of stress, and difficulties of the sense of coherence is important to identify (2). People providing care for others with advanced PD have demonstrated diminished quality of life, especially as the illness progresses $(3,4)$. A number of studies also demonstrated caregivers' burdens as reduced mental health and increased signs of depression (5-7). Loneliness seems to be common, and sleeping problems, especially at increased duration of the illness and increased caregiver burden (8-10). A number of scales are used for the assessment of the caregivers' burdens in $\mathrm{PD}$, and overall they point out various stressfull situations for both patient and close relative $(4,6$, 10, 11). Recently, a 29-item Parkinson Disease Questionnaire for Carers was developed and is described as a short, meaningful quality of life instrument covering areas of specific salience and concern to the carers (3).

As the progressive nature of PD often places a heavy burden on caregivers' emotional well being, the need for caregiver support, intervention and educational programs is essential to reduce strain, as well as to achieve better coping and adaptation strategies (7). For a better understanding of the caregivers' burden, the Caregiver Grief Inventory (12) has been used, finding e.g. "pre-death" grief reactions among 17 per cent of PD carers and an increase with the progression of the severity of the disease (7). Such "little deaths" were, according to Roland and coworkers (5), referring to caregivers' subjective reports of the Parkinson's disease progress, e.g. to feelings of independence and diminishment of social networks.

To reach improved health outcomes of bereavement, focus should include the period both before and after the death of a loved one. Coping with and adapting to the terminal decline 
of a close relative, i.e. anticipatory grief, is now being studied for an increasing number of diseases (13-15).

Rather few studies have, however, focused on the caregivers' burden, quality of life, and anticipatory, preparatory grief among the relatives of PD patients in comparison with relatives' experiences of other fatal diseases (16). Thommessen and coworkers (17) found that spouses caring for patients with dementia, stroke, and PD perceived a similar type and level of psychosocial burden, independent of the disease. The cognitive functioning of the patient seemed particularly important, especially when caring for patients with stroke or PD. Proper detection and management of depression in primary care is imperative for relatives of patients with Alzheimer's disease, PD and stroke.

More recent studies point to the problem of comparisons between diseases (17). Stereotypes of the meaning and timing of palliative care were common, many viewing it as being synonymous with cancer and not applicable to a person with PD (1). Carter and coworkers (14) stated that in PD the negative impact of providing care has been referred to as 'caregiver strain'. Reactions of grief have, however, not been explored among PD caregivers who are living with the ill person in their home. Understanding aspects of grief may offer new insights for future intervention.

Within this latter intention, the present study was performed. In a former study (18), we studied the anticipatory grief of relatives of cancer patients using the Anticipatory Grief Scale assessment, AGS. In a later comparison study using the same instrument, we compared anticipatory grief of relatives of persons with dementia and terminal cancer (19). In the present study we chose the same instrument and applied it on relatives of persons with PD and compared reactions and feelings with subjects suffering from dementia. To our knowledge, the use of the Anticipatory Grief Scale (AGS) has so far not been used as a questionnaire for self-assessing feelings and behaviour of relatives of $\mathrm{PD}$ patients.

\section{Methods}

\subsection{Participants}

Inquires were sent to PD caregiver support groups in Sweden to be handed out to the members at their meetings. The respondents were asked to answer the questions at home. The answers were returned by mail in prepaid envelopes to the hospital address of the project leader.

\subsubsection{Respondents with Relatives with Parkinson's Disease}

Responses were received from 44 men and women within the age range of 44 to 88 years (the average age being 71.6 years, $\mathrm{SD}=8.6)$. The age range of the PD subjects was 45 to 92 years (the average age being 67.5 years, $S D=10.4$ ).

\subsubsection{Respondents with Relatives with Dementia}

The collection of data was performed by inquires handed out by the nurses in charge at dementia units and nursing homes in 3 Swedish cities (19). The respondents were 53 men and women (age range 61-91 years, the average age being 62.3 years, $\mathrm{SD}=13.3 \mathrm{yrs}$ ). The age range of the persons with dementia was 40 to 85 years, the average being 81.7 years $(\mathrm{SD}=7.7 \mathrm{yrs})$, Twenty-six had Alzheimer disease, 11 had vascular dementia, and 16 had mixed forms and other dementia diagnoses.

\subsection{Measures}

\subsubsection{The Anticipatory Grief Scale}

In this study anticipatory grief was evaluated by the Anticipatory Grief Scale (AGS) (20). This is a 27-item selfadministered questionnaire assessing reactions to and coping with expected death and can be completed in 10 to 15 minutes. The responses range from "Strongly disagree", "Disagree", "Somewhat agree, "Agree", and "Strongly agree". In the data analyzes, the answers were dichotomized into two steps "Agree" and "Disagree". The AGS scale represents the major domains cited in the literature on grief. It was intended for relatives of persons diagnosed with dementia, but the wording could be changed to other disease diagnosis, for example cancer (20). The internal consistency of AGS using Cronbach alpha, the alpha level for the scale has been shown to be good at .84. The advantage of using the AGS is that clinicians, social workers, and counselors can identify the problems an individual may be experiencing before the death of the relatives and that proper interventions can take place to avert long-term negative outcomes after the death.

\subsubsection{Assessments of Background Variables}

Background variables were the age of the respondents and their relatives with PD, the duration of the disease $(<9$ years and $\geq 10$ years), the respondents' perceived quality of care, and the respondents' own perceptions of the health condition of the PD patient. The estimations made by the respondents about the health condition of their relative with PD (ranging from Very good, Good, Not so good, Rather bad, and Bad) were divided into two groups in the data analyses (Good and Bad). Likewise, the perceived quality of care that was offered the PD patients was also divided into two groups (Good and Bad).

\subsubsection{Statistics}

The background variables (the age of respondent and the PD patient, the length of the disease, the perceived health condition of the PD patient, and the quality of care offered him/her) were tested against the AGS answers with Fisher exact test. Statistical comparisons between characteristics of the answers on the AGS of the two groups (the PD and the demented subjects) were not done, as the sample sizes of the groups of the relatives cannot be considered sufficiently representative.

\section{Results}

\subsection{Assessments Made by the Relatives of the Patients with Parkinson's Disease}

Very negative and also less or moderately negative 
anticipatory grief reactions were found among the relatives of the PD patients (Table 1). Preoccupation with and tearfulness when thinking of the course of the illness, missing past times and the relative's former personality, as well as the loss of togetherness and the final loss were frequent negative reactions and thoughts. However, many told that they had adjusted to the illness, had personal resources to cope with the future, and were even planning for coming times. Almost four of five relatives stated that they were functioning about as well as before their relative was diagnosed with PD.

Table 1. The results on the Anticipatory Grief Scale (AGS) of 44 close relatives of patients with Parkinson's Disease and 53 close relatives of persons with dementia

\begin{tabular}{|c|c|c|}
\hline & \multicolumn{2}{|c|}{$\begin{array}{l}\text { Agree }(\%) \\
\text { Relatives of persons with }\end{array}$} \\
\hline & Parkinson's & Dementia \\
\hline 1. I daydream about how life with my relative was before the diagnosis of illness was made. & 71 & 79 \\
\hline 2. I feel close to my relative who has Parkinson/Dementia. & 59 & 87 \\
\hline 3. I seem to be more irritable since the diagnosis was made for my relative. & 66 & 47 \\
\hline 4. I am preoccupied with thoughts about my relative and his or her illness. & 90 & 75 \\
\hline 5. I have discovered new personal resources since my relative's illness was diagnosed. & 77 & 74 \\
\hline 6 . I very much miss my relative the way he or she used to be. & 93 & 91 \\
\hline 7. I have felt very much alone since the diagnosis was made for my relative. & 44 & 62 \\
\hline 8. I am able to move ahead with my life. & 88 & 94 \\
\hline 9. I blame myself for my relative's illness. & 13 & 4 \\
\hline 10. I find it hard to concentrate on my work since the diagnosis was made for my relative. & 45 & 51 \\
\hline 11. I have the personal resources to help me cope with my relative and his or her illness. & 78 & 87 \\
\hline 12. I have periods of tearfulness as I think about the course of my relative's illness. & 85 & 81 \\
\hline 13. I feel detached from my relative. & 12 & 30 \\
\hline 14. I feel a need to talk to others regarding my relative's illness. & 84 & 66 \\
\hline 15. I feel it is unfair that my relative has Parkinson/Dementia. & 93 & 81 \\
\hline 16. I find it hard to sleep since the diagnosis was made for my relative. & 56 & 47 \\
\hline 17. No one will ever take the place of my relative in my life. & 90 & 85 \\
\hline 18. I avoid some people since my relative was diagnosed with Parkinson/Dementia. & 27 & 11 \\
\hline 19. I feel I have adjusted to my relative's illness. & 88 & 89 \\
\hline $\begin{array}{l}\text { 20. Since my relative was diagnosed with Parkinson/Dementia, I find it more difficult to get along with } \\
\text { certain people. }\end{array}$ & 23 & 11 \\
\hline 21. I wonder what my life would be like if my relative had not been diagnosed with Parkinson/Dementia. & 67 & 55 \\
\hline 22. I feel more competent since my relative was diagnosed with Parkinson/Dementia. & 46 & 60 \\
\hline 23. I get angry when I think about my relative having Parkinson/ Dementia. & 47 & 46 \\
\hline $\begin{array}{l}\text { 24. Since the diagnosis was made for my relative, I don't feel interested in keeping up with the day-to-day } \\
\text { activities (TV, newspapers, and friends). }\end{array}$ & 17 & 12 \\
\hline 25. I am unable to accept the fact that my relative has a diagnosis of Parkinson/Dementia. & 61 & 63 \\
\hline 26. I am now functioning about as well as before my relative was diagnosed. & 78 & 77 \\
\hline 27. I am planning for the future. & 81 & 84 \\
\hline
\end{tabular}

\subsubsection{Correlations between the Background Variables of the Relatives of Patients with Parkinson's Disease and the AGS Statements}

There were no significant differences between the duration of the disease and the AGS answers. A perceived lower quality of care of the relative with Parkinson's was positively related to the statements "I seem to be more irritable since the diagnosis was made for my relative" ( $p=0.0342)$, and "I am preoccupied with thoughts about my relative and his or her illness" ( $p=0.0189)$. A perceived bad condition of the person with Parkinson's at the time for questioning was positively related to the statements "I have felt very much alone since the diagnosis was made for my relative" $(\mathrm{p}=0.0435)$ and "I feel a need to talk to others regarding my relative's illness" $(\mathrm{p}=0.0109)$, and negatively related to "I am now functioning about as well as before my relative was diagnosed" $(\mathrm{p}=0.0121)$ and "I am planning for the future" $(\mathrm{p}=0.0168)$.

\subsection{The AGS Assessments of the Relatives of Persons with $P D$ and Persons with Dementia}

Many similarities were seen on most of the statements of the AGS, as the percentage of the relatives who agreed to the statements in both groups did not differ much (Table 1). To a similar extent in both groups, the respondents daydreamed of their lives before the illness, felt angry that their relative had become ill, felt like crying thinking of the course of the illnesses, missed the person before the onset of the illness, found it unfair that the relative had got the disease, thought nobody could ever take his or her place, had difficulties accepting the illness, had sleeping problems and difficulties concentrating, were preoccupied by thoughts of their relatives, and were not interested in keeping up with the dayto-day activities. Also to a similar extent in the two groups, they had discovered new personal resources since the relative's illness had been diagnosed, had adjusted to the 
situation, were functioning about as well as before the relative had been diagnosed, could move ahead with their lives, felt competent after the relative had been diagnosed with dementia, and felt they had the personal resources to helped them cope with their relative and his or her illness.

\section{Discussion}

The responses on the AGS seemed to be rather similar for the PD and dementia groups. However, no statistical comparisons were made, as there may be limitations how representative the study groups are, and there are differences in the procedure of collecting the answers.

Many relatives in the two illness groups revealed longing for past days before the onset of illness, looked back in thoughts and memories, had difficulties holding back their tears, and seemed to seek contact with other people for relief through talking about the situation. At the same time, many seemed to gather their personal resources to cope with the future they feared for and adjust to the situation - presently and ahead. Contradictory but understandable statements tended to exist for denial of the illness and good ability to move ahead.

The reason for this may be similar age range of the patients, that both conditions had a long-term pattern, and were not immediately life threatening. The caregiver burden has been reported to be more depending on the emotional relationship with the ill than if he or she is a spouse or offspring (21). Spouses caring for relatives with e.g. dementia and PD tend to perceive a similar type and level of psychosocial burden, independent of disease (10). In the present study, closeness and preoccupation with thoughts about the ill relative seemed common, as longing back to former life together, and anger about life's unfairness of hurt by the disease. As also a majority of the responders also felt that it would be impossible to replace the ill person with anyone else, one may assume very tight family and emotional bonds.

As the ill person's cognition deteriorates in diseases like dementia and PD, their life companions often miss the communication, the companionship, and the support they used to offer one another. Also, the present two groups frequently stated that no one else could ever take the place of the ill relative. However, more relatives to the demented persons stated closeness to their relatives compared with the relatives of PD persons, being somewhat contradictory to the common frequent statements in both groups about missing their relative, their tearfulness, feelings of unfairness, and non-acceptance of getting the disease.

The cognitive functioning of the PD and dementia patients, however not measured in the present study, is a particularly important factor for the quality of the relationship according to Thommessen (17). In several studies the quality of life of the family caregiver is furthermore negatively affected by sleeping and concentration problems, anger, lowered mood, depression, and even economic loss $(9,10,15,22,23)$. Also found in the present study were conditions like irritability, concentration difficulties, sleeping problems, and decreased personal competence, as preoccupation with the illness and irritability about low quality of care.

According to McRae and coworkers (9) loss of reciprocity in the two illness groups often leads to loneliness, modification of habits, longing for past experiences of togetherness, and the former personality of the ill. This seemed to be the case also in the present study, as many daydreamed of life before the onset of the illness. As demonstrated in other studies $(7,12)$, feeling lonely and need to talk to others about the relative's illness corresponded with a need of support. Attending caregiver support groups may lessen loneliness and increase the perception of support (15), as the responders in the present study used to. Findings of harmful factors to the caretaker should be reflected in clinical guidelines and programs for the management of PD $(13,24,25)$.

Avoidance of others and detachment from the relative was not frequent in any of the groups. Neither was self-blame for the relative's illness, which could be found in cancer studies with statements like: "Why didn't I get him to the doctor in time?" (Authors' unpublished experience among relatives of cancer patients). The characteristics of both PD and dementia may, however, be hard to detect for close relatives especially in the early stages of the illness.

Carter and co-workers (14) found that younger spouses (40-55 years of age) were at greater risk for negative consequences of the care situation reporting more strain from lack of personal resources, lower levels of mutuality and rewards of meaning than older (greater than 70 years) spouses. According to Schrag (6), however, there was no difference in caregiver-burden between younger and older caregivers, or between male and female caregivers. In the present study, the age of the PD's caregivers did not relate to the AGS outcome.

In the present study based on two small populations, the reactions and feelings among the respondents were not statistically compared, but the results concerning anticipatory grief seemed to be similar in many aspects. An increasing number of assessments have been used to estimate the stress among caregivers of both PD and dementia patients $(3,9,17$, 23). Similarities in caregivers' emotional burden are shown in many of these studies, as suggestions how to lessen the feelings of deprivation, strain, and depression, to ease the burden and increase the quality of life. The negative concomitants of having a loved one getting PD or a dementia diagnosis are named for example caregivers' grief reactions, pre-death grief, or preparatory grief (7).

In order to keep questions about background variables as few as possible and easy to assess for the PD relatives, variables as ADL abilities, cognitive functioning and neuropsychiatric symptoms were omitted. This could have strengthened the study. The various places of living (at home regarding the $\mathrm{PD}$ patients and at institution regarding the demented persons), i.e. rather different study group, might also have influenced the outcome. Further studies on greater populations regarding these aspects are recommended and 
would certainly increase the understanding of families' anticipatory grief at these, however different, severe illnesses of terminal character.

Surprisingly many respondents among the PD relatives seemed to be adjusted and well-functioning in daily life, have resources left, be able to move on with their lives, and plan for the future. Also, lack of interest with daily news and activities was sparsely reported, which may tell us that sacrifice and other feelings of burden around the disease concomitants either were withheld or did not come through as in other studies $(7,12,26)$. Possibly this says that many of responders in our study had good insight, were accommodated to the situation, found help in the support groups, and after all had the energy and mental prerequisites to follow their relatives' further struggles.

\section{Acknowledgments}

Thanks are due to all those who have helped us answering and collecting the questionnaires. We are also grateful to Valter Sundh, BSc, for statistical discussions and invaluable help with the data processing.

\section{Funding}

The authors disclosed receipt of the following financial support for the research, authorship, and/or publication of this article. This research was facilitated by grants from the Parkinson Foundation in Sweden.

\section{References}

[1] McLaughlin D, Hasson F, Kernohan WG, Waldron M, McLaughlin M, Cochrane B, Chambers H. Living and coping with Parkinson's disease: perceptions of informal carers. Pall Med 2011;25(2):177-182.

[2] Andrén S, Elmståhl S. The relationship between caregiver burden, caregivers' perceived health and their sense of coherence in caring for elders with dementia. J Clin Nurs 2008;17(6):790-799.

[3] Jenkinson C, Dummett S, Kelly L, Peters M, Dawson J, Morley D, Fitzpatrick R. The development and validation of a quality of life measure for the carers of people with with Parkinson's disease (the PDQ-Carer). Parkinsonism Relat Disord 2012 Jun;18(5):483-487.

[4] Leroi I, McDonald K, Pantula H, Harbishettar V. Cognitive impairment in Parkinson disease: impact on quality of life, disability, and caregiver burden. J Geriatr Psychiatry Neurol 2012;25(4):208-214.

[5] Roland KP, Jenkins ME, Johnson AM. An exploration of the burden experienced by spousal caregivers of individuals with Parkinson's disease. Mov Disord 2010;25(2):189-193.

[6] Schrag A, Hovris A, Morley D, Quinn N, Jahanshahi M. Caregiver-burden in Parkinson's disease is closely associated with psychiatric symptoms, falls, and disability. Parkinsonism Relat Disord 2006;12(1):35-41.
[7] D'Amelio M, Terruso V, Palmeri B, Di Benedetto N, Famoso G, Cottone P, Aridon P, Ragonese P, Savettieri G. Predictors of caregiver burden in partners of patients with Parkinson's disease. Neurol Sci 2009;30(2):171-174.

[8] Carter JH, Lyons KS, Lindauer A, Malcom J. Pre-death grief in Parkinson's caregivers: a pilot survey-based study. Parkinsonism Relat Disord. 2012;18 Suppl 3:S15-18.

[9] McRae C, Fazio E, Hartsock G, Kelley L, Urbanski S, Russell D. Predictors of loneliness in caregivers of persons with Parkinson's disease. Parkinsonism Relat Disord 2009;15(8):554-557.

[10] Pal PK, Thennarasu K, Fleming J, Schulzer M, Brown T, Calne SM. Nocturnal sleep disturbances and daytime dysfunction in patients with Parkinson's disease and in their caregivers. Parkinsonism Relat Disord 2004;10(3):157-168.

[11] Lökk J. Caregiver strain in Parkinson's disease and the impact of disease duration. Eur J Phys Rehabil Med 2008;44(1):3945.

[12] Tan SB, Williams AF, Morris ME. Experiences of caregivers of people with Parkinson's disease in Singapore: a qualitative analysis. J Clin Nurs 2012;21:2235-2246.

[13] Marwit SJ, Chibnall JT, Dougherty R, Jenkins C, Shawgo J. Assessing pre-death grief in cancer caregivers using the Marwit-Meuser Caregiver Grief Inventory (MM-CGI). Psychooncology 2008;17:300-303.

[14] Carter JH, Lyons KS, Stewart BJ, Archbold PG, Scobee R. Does age make a difference in caregiver strain? Comparison of young versus older caregivers in early-stage Parkinson's disease. Mov Disord 2010;25:724-730.

[15] Coombs MA. The mourning before: can anticipatory grief theory inform family care in adult intensive care? Int $\mathrm{J}$ Pall Nurs 2010;16:580-584.

[16] Holtslander LF, McMillan SC. Depressive symptoms, grief, and complicated grief among family caregivers of patients with advanced cancer three months into bereavement. Oncol Nurs Forum 2011;38:60-65.

[17] Thommessen B, Aarsland D, Braekhus A, Oksengaard AR, Engedal K, Laake K. The psychosocial burden on spouses of the elderly with stroke, dementia and Parkinson's disease. Int J Geriatr Psychiatry 2002;17(1):78-84.

[18] Johansson ÅK, Grimby A. Anticipatory Grief Among Close Relatives of Patients at Hospice and Palliative Wards. Am J Hosp Pall Med 2012;29:134-138.

[19] Johansson ÅK, Sundh V, Wijk H, Grimby A. Anticipatory grief among close relatives of persons with dementia in comparison with close relatives of patients with cancer. Am J Hosp Pall Med 2013;30:29-34.

[20] Theut SK, Jordan L, Ross LA, Deutsch SI. Caregiver's anticipatory grief in dementia: a pilot study. Int J Aging Hum Develop 1991;33:113-118.

[21] Liu NC, Lai EYL. Find a way out: bereavement support in Taiwan hospice. Support Care Cancer 2006;14:4-10.

[22] Shin H, Lee JY, Youn J, Kim JS, Cho JW. Factors contributing to spousal and offspring caregiver burden in Parkinson's disease. Eur Neurol 2012;67:292-296. 
[23] Ozdilek B, Gunal DI. Motor and non-motor symptoms in Turkish patients with Parkinson's disease affecting family caregiver burden and quality of life. J Neuropsychiatry Clin Neurosci 2012;24(4):478-483.

[24] Martínez-Martín P, Arroyo S, Rojo-Abuin JM, RodriguezBlazquez C, Frades B, de Pedro Cuesta J. Burden, perceived health status, and mood among caregivers of Parkinson's disease patients. Mov Disord 2008;23:1673-1680.

[25] A'Campo LE, Wekking EM, Spliethoff-Kamminga NG, Le Cessie S, Roos RA. The benefits of a standardized patient education program for patients with Parkinson's disease and their caregivers. Parkinsonism Relat Disord 2010;16(2):89-95.
[26] Morley D, Dummett S, Peters M, Kelly L, Hewitson P, Dawson J, Fitzpatrick R, Jenkinson C. Factors influencing quality of life in caregivers of people with Parkinson's disease and implications for clinical guidelines. Parkinsons Dis 2012;2012:190901. doi: 10.1155/2012/190901. Epub 2012 Dec 20.

[27] Razali R, Ahmad F, Rahman FN, Midin M, Sidi H. Burden of care among caregivers of patients with Parkinson disease: a cross-sectional study. Clin Neurol Neurosurg 2011;113(8):639-643. 